\title{
Correlation between COVID-19 case fatality rate and percentage of $B C G$ vaccination: is it true the vaccine is protective?
}

\author{
Aliae A. R. Mohamed Hussein ${ }^{1 *}$ (D, Marwa Rashad Salem², Samar Salman ${ }^{3}$, A F Abdulrahim ${ }^{4}$, Nasrallah A. Al Massry ${ }^{5}$, \\ Mahmoud Saad ${ }^{1}$, Nesrine Ben Hadj Dahman ${ }^{6}$ and Ahmed Negida 7,8
}

\begin{abstract}
Background: The observations of some recent epidemiological studies offer hope for a reduced impact of COVID19 for countries which practice universal BCG vaccination policy.

Main body: This report provides a correlation between the case fatality rates of COVID-19 and the percentage of BCG vaccination coverage in 183 most affected countries. The main objective of this observational ecologic report is to evaluate possible effects of the previous BCG vaccination in different populations and the epidemic outcomes specially the rates of severe/critical cases and case fatalities. The analysis is preliminary since it is based on constantly rolling data while the COVID-19 pandemic is still unfolding.

Conclusion: Our findings seem to support the fact that an older BCG vaccine may have a protective role in avoiding severe/critical SARS-CoV2 pneumonia and relatively decrease its fatalities.
\end{abstract}

Keywords: Coronavirus disease, SARS-Cov-2, COVID-19, BCG vaccination, Tuberculosis vaccine

\section{Background}

Several reports showed that exaggerated immune response of COVID-19 contributes to severe disease [1]. On May 19th, 2020, the number of confirmed cases is 4, 956,733 with total deaths 323,095 , with a fatality rate of 0.22 per million. All over the world, twenty-six of the 179 countries had unknown status regarding BCG vaccination, while 132 have current BCG vaccination programs and 21 have no national BCG program.

As the BCG vaccine is already approved for human use, it is known to boost the immune system and modulate the exaggerated immunity response against tuberculosis [2]. It provides protection against a range of infections, not simply the mycobacterium for which the vaccine was originally developed [3] but also a range of conditions, including respiratory infections (bacterial

\footnotetext{
*Correspondence: aliaehussein@gmail.com; aliaehussein@aun.edu.eg ${ }^{1}$ Assiut University Hospitals, Assiut 71515, Egypt

Full list of author information is available at the end of the article
}

and viral), neonatal sepsis, and fevers [4], and geriatric acute upper respiratory tract infections [5].

It is hypothesized that, until a specific vaccine is developed, SARS-CoV-2 vulnerable populations could be immunized with BCG vaccines. Such a strategy would also be suitable for frontline health personnel [6].

The aim of this perspective is to correlate between the COVID-19 case fatality rates, serious/critical case percentage, and percentage of national BCG vaccine coverage.

In methodology, to evaluate the effect of BCG vaccine, we included the BCG coverage percentage in 183 countries (countries which have never included BCG vaccine in their national immunization program (NIP), countries which had included the vaccine in the past but do not do so currently, and countries who currently have BCG vaccine included in their NIP) and the COVID-19 infection rate, mortality levels, prevalence of serious/critical cases, and case fatality rates (Table 1). Pearson correlation was done to test the association of these variables.

\section{Springer Open}

(๑) The Author(s). 2020 Open Access This article is licensed under a Creative Commons Attribution 4.0 International License, which permits use, sharing, adaptation, distribution and reproduction in any medium or format, as long as you give appropriate credit to the original author(s) and the source, provide a link to the Creative Commons licence, and indicate if changes were made. The images or other third party material in this article are included in the article's Creative Commons licence, unless indicated otherwise in a credit line to the material. If material is not included in the article's Creative Commons licence and your intended use is not permitted by statutory regulation or exceeds the permitted use, you will need to obtain permission directly from the copyright holder. To view a copy of this licence, visit http://creativecommons.org/licenses/by/4.0/. 
Table 1 Correlations of BCG coverage percentage in 183 countries (countries that follow a national BCG immunization program and those that did not have or have ceased their national BCG vaccination programs) and the number of cases/1000 population and number of serious and critical cases/1000 and deaths/1000 population and case fatality rates (in 121 countries)

\begin{tabular}{|c|c|c|c|c|c|c|}
\hline Variable & & BCG coverage $\%$ & Cases/1000 population $^{\mathbf{1}}$ & Serious cases/1000 population ${ }^{\mathbf{2 , 3}}$ & Deaths/1000 population ${ }^{4}$ & $C F R^{5}$ \\
\hline \multirow[t]{3}{*}{ BCG coverage } & Pearson correlation & 1 & $-0.592^{* *}$ & $-0.256^{* *}$ & $-0.608^{* *}$ & $-\overline{0.388^{* *}}$ \\
\hline & Sig. (2-tailed) & & $<0.001$ & 0.001 & $<0.001$ & $<0.001$ \\
\hline & $N$ & 180 & 180 & 180 & 180 & 121 \\
\hline \multirow[t]{3}{*}{ Death rate } & Pearson correlation & $-0.608-^{* *}$ & 1 & $0.321^{* *}$ & 1 & 1 \\
\hline & Sig. (2-tailed) & $<0.001$ & - & $<0.001$ & 1 & - \\
\hline & $N$ & 180 & 183 & 183 & 183 & 121 \\
\hline
\end{tabular}

Coronavirus related statistics were based on data obtained from https://www.worldometers.info/coronavirus/ (according to the latest update on May 2nd, 2020, 20:44 GMT). BCG related statistics were based on Global Health Observatory data repository, BCG Immunization coverage estimates by WHO region,

2018. Doi:10.1371/journal.pmed.1001012.g002

${ }^{1}$ Statistically significant negative moderate correlation $(R=-0.592)$ between BCG coverage and number of cases/1000 (incidence rate) of COVID-19 among the studied countries, $P<0.001$

${ }^{2}$ Statistically significant negative correlation $(R=-0.25)$ between BCG coverage and number of serious cases/1000 (incidence rate of COVID-19 serious cases) among the studied countries, $P=0.001$

${ }^{3}$ Statistically significant positive correlation $(R=0.32)$ between death rate and incidence rate of COVID-19 serious cases among the studied countries at $P$ value $<0.001$

${ }^{4}$ Statistically significant negative moderate correlation $(R=-0.6)$ between BCG coverage and death rates at $P$ value $<0.001$

${ }^{5}$ Statistically significant negative weak correlation $(R=0.38)$ between BCG vaccination coverage and case fatality rate of COVID-19 among the studied countries at $* *=P$ value $<0.001$

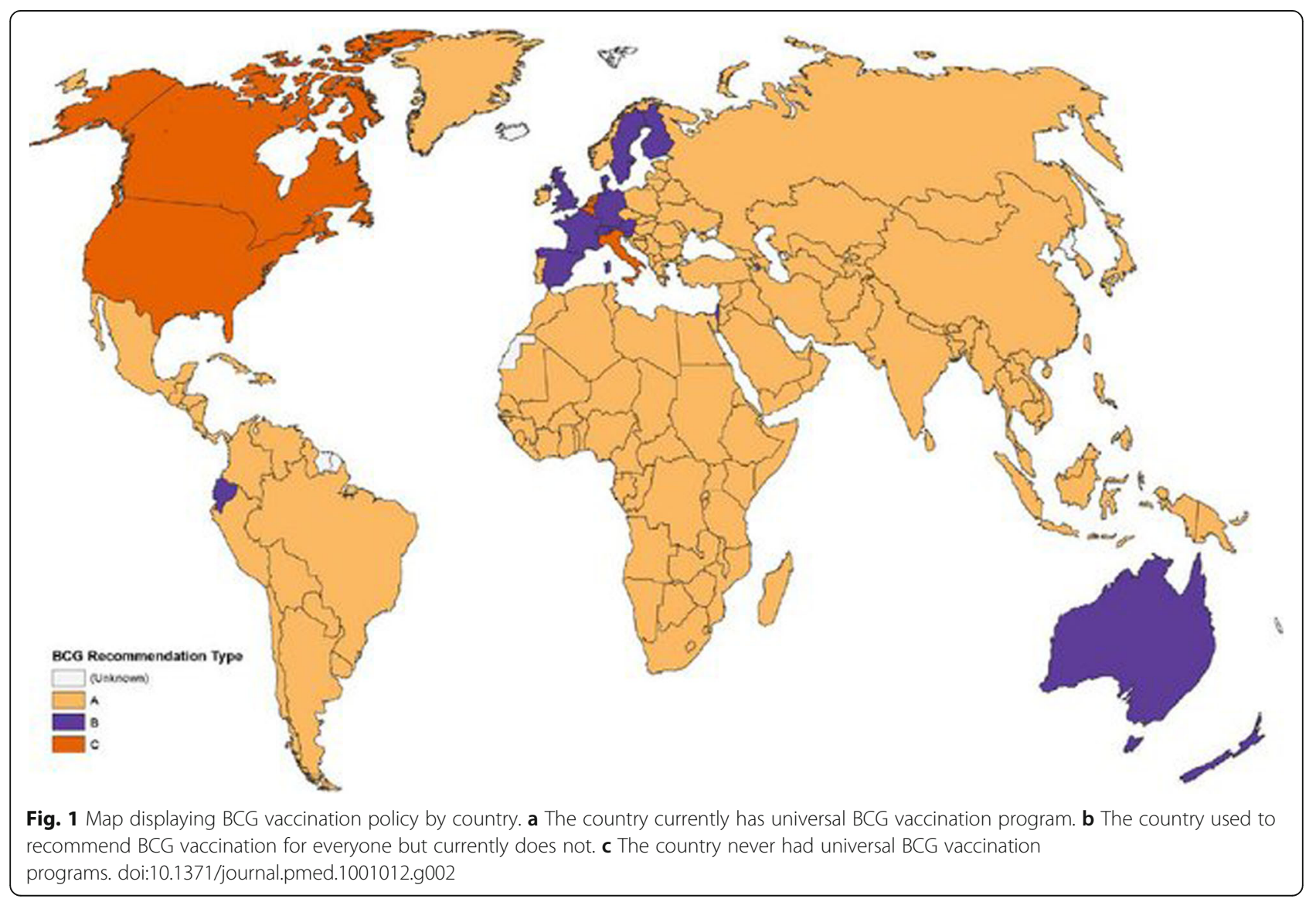


We used Worldometer to collect national COVID-19 attributable data as of May 2, 2020, which includes "cases per million" and "deaths per million" attributes for the top 183 countries reporting highest case events [7]. We used the same source to collect information on COVID-19 testing data at country level. For BCG coverage, we used WHO-UNICEF estimates of BCG coverage (last update 15 July 2019) [8] (Figs. 1 and 2).

Ethical approval was not required for this report of existing peer reviewed literature.

\section{Main text}

As for data published from the WHO first announcement of the disease to 18th May 2020, when we analyzed the available data on BCG coverage (10, supplement 1 ), WHO COVID-19 status reports [1] in 183 countries (Fig. 1) and correlated the incidence and mortality patterns from COVID-19 among different countries (Table 1); the following data were noticed. There is a statistically significant negative moderate correlation between BCG coverage and death rates $(P<0.001)$ as well as negative correlation between BCG coverage and incidence rate of all cases as well as serious and critical cases of COVID-19 among the studied countries $(P=0.001)$.

Since the beginning of the pandemic, it was noticed that countries with BCG vaccination program appear to have a lower incidence and death rate from COVID-19 as compared to countries without such a program [9]. Reports showed that morbidity and mortality due to COVID-19 are associated with early adoption or universal coverage of BCG vaccination. They suggested that BCG might show long-lasting protection against SARS$\mathrm{CoV}-2$ by reduction in the incidence of the respiratory tract infections in children, antiviral effects, and decrease viremia in experimental animals $[3,10]$. The vaccine may slow down the spread and progression of symptoms and decrease the number of total cases and deaths per one million [11]. There is a significant difference in the

\section{Total confirmed COVID-19 cases per million people, Apr 30, 2020}

The number of confirmed cases is lower than the number of total cases. The main reason for this is limited testing.
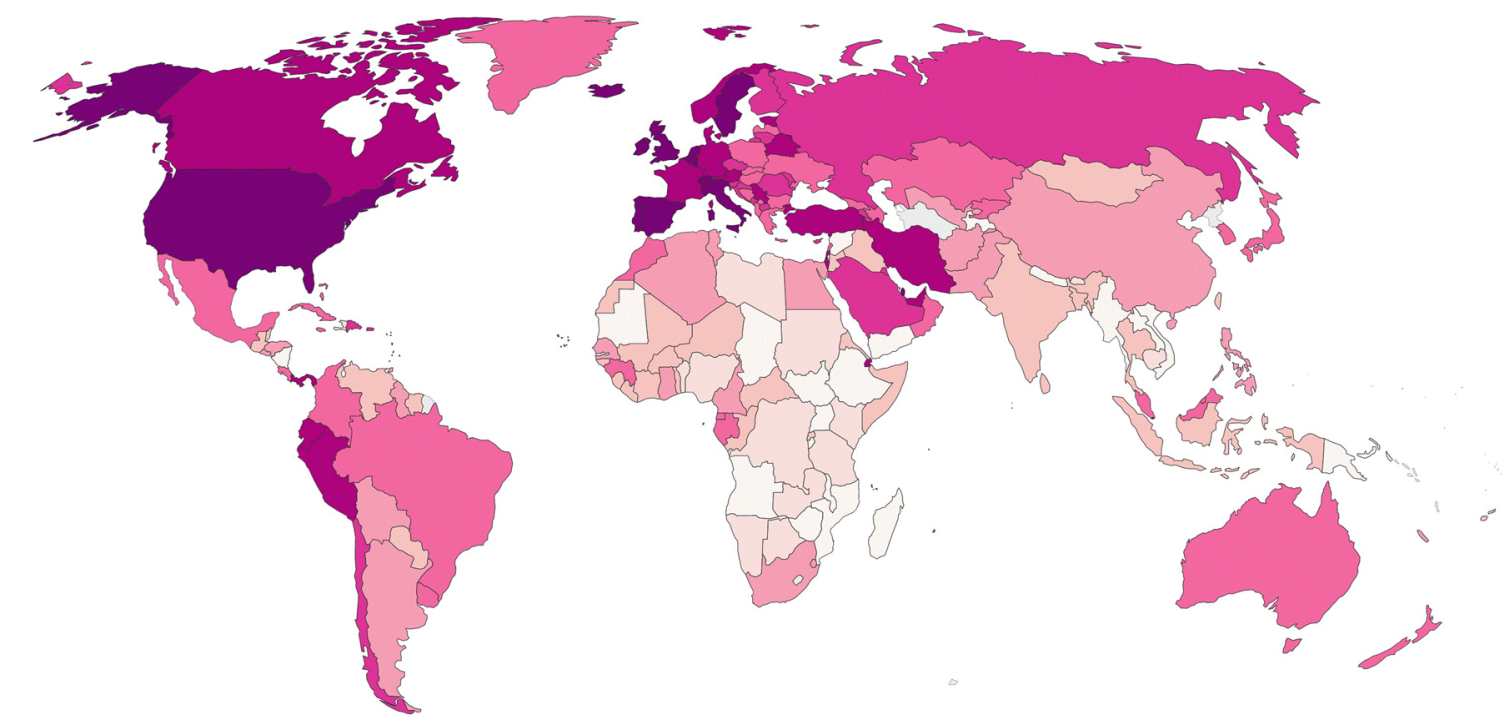

No data 0

5

10

50

100

500

1,000

2,000

$>5,000$

Source: European CDC - Situation Update Worldwide - Last updated 3rd May, 11:45 (London time)

OurWorldInData.org/coronavirus • CC BY

Fig. 2 Map of the COVID-19 verified number of infected per capita as of 2nd May 2020. Since this is a rapidly evolving situation, new cases may not be immediately represented visually. Refer to the primary article 2019-20 coronavirus pandemic or the World Health Organization's situation reports for most recent reported case information. Every country bigger than 3 million $\mathrm{km}^{2}$ has been split up into its first level administrative division for better visualization of the spread of the epidemic. > 5000 cases per million inhabitants. 2000-5000 cases per million inhabitants. 5002000 cases per million inhabitants. 200-500 cases per million inhabitants. 50-200 cases per million inhabitants. > 0-50 cases per million inhabitants. No reported cases, no population, or no data available 
COVID-19-related fatality rates (CFR) between countries with high COVID-19 disease burden and those with BCG revaccination policies [12]. The mortality and reported COVID-19-attributable mortality (COVID-19-related deaths) among BCG-using countries is 5.8 times lower [95\% CI 1.8-19.0] than in non-BCG-using countries [13] and in countries with mandated BCG vaccinations compared to countries that terminated BCG vaccination policies before 2000 [14].

However, many reports do not support the BCG hypothesis that all existing claims are based on crosscountry correlations $[15,16]$. When comparing the same stage in the epidemic, a study does not find any significant difference in COVID-19 severity between countries with or without BCG policies [17]. A recent compares the incidence of COVID-19 infection among vaccinated versus unvaccinated individuals and showed a similar rate of positive test results for SARS-CoV-2 compared with no vaccination [18]. However, this study compared the two groups in terms of laboratory confirmed COVID-19 by RT RNA PCR. But if we assume that BCG vaccinated individuals had more/less asymptomatic infections, the results of this study will be biased as many positive cases will be counted as negative in the analysis. This is called a misclassification error. A future study comparing the two groups with serology testing for antiSARS-CoV-2 antibodies will be more appropriate.

\section{Conclusions}

BCG vaccine correlates with COVID-19 case fatality rates and probably offers protection against severe/critical cases of SARS-CoV-2. Recommended work through randomized controlled trials to determine how fast a BCG-induced protective immune response against COVID-19 develops is needed to validate its use as immune prophylaxis for more exposed population as healthcare workers.

The findings of the current report should be viewed within the limitation that these data are rapidly changeable; the majority of the studies use publicly available data repositories such as Worldometer to source COVID-19-related data [4]. In the same time, most studies source country-wise BCG-related data using outlets such as BCG World Atlas (http://www.bcgatlas.org/) [8] and other sources, such as reports and datasets published by the World Health Organization, World Bank, and United Nations. Another limitation is that there may be several confounding issues such as limited testing and reporting in many countries. However, these data are derived from 183 countries out of 210 countries reported globally, as of 2:00 a.m. CEST, 4 May 2020. Other limitations include the populations are not stratified by age and comorbidities which may be confounders in case fatality rate from COVID-19. COVID-19 managing protocol is different in different countries. Recent mutations may have occurred in coronavirus, and subtypes caused SARS-CoV-2 disease with different virulence. Lastly, the acquired immunity from BCG lasts for different periods, and there is a strong recommendation to test its validity by tuberculin test or QuantiFeron gamma in COVID-19 patients.

\section{Acknowledgements \\ The authors are working as part of COVID-19 MENA Response Research. The team acknowledges Dr. A Sedrak, Associate Professor of Public Health, Cairo University, for her help in statistical analysis.}

\section{Authors' contributions}

A MH was the principle investigator, collected data, formulated the results, wrote the discussion, and did the final edits. MS was responsible for writing discussion and statistics. SS, AF A, NM, and M S were responsible of data acquisition and review search. NB revised the statistics and data collection, and AN formulated the idea of the work and revised the statistics. All authors revised and approved the final manuscript.

\section{Funding}

None.

\section{Availability of data and materials}

Available online data.

Ethics approval and consent to participate

$\mathrm{N} / \mathrm{A}$ (The study is ecologic perspective, and report does not need ethical approval).

\section{Consent for publication}

All authors read, revised, and approved the submission.

\section{Competing interests}

We declare that we do not have any conflict of interests.

\section{Author details}

${ }^{1}$ Assiut University Hospitals, Assiut 71515, Egypt. ${ }^{2}$ Epidemiology and Public Health, Cairo University, Giza, Egypt. ${ }^{3}$ Dermatology and Venerology, Faculty of Medicine, Tanta University, Tanta 30255, Egypt. ${ }^{4}$ Assiut University, Assiut 71515, Egypt. ${ }^{5}$ Faculty of Medicine, Al-Quds University- Palestine, Al-Azhar branch- Gaza, Gaza, State of Palestine. ${ }^{6}$ Faculty of Medicine of Tunis, Tunis, Tunisia. ${ }^{7}$ Neurosurgery Department, Zagazig University Hospitals, Zagazig University, Sharkia, Egypt. ${ }^{8}$ School of Pharmacy and Biomedical Sciences, University of Portsmouth, Portsmouth, UK.

Received: 29 May 2020 Accepted: 27 July 2020

Published online: 09 September 2020

\section{References}

1. Shi Y, Wang Y, Shao C et al (2020) COVID-19 infection: the perspectives on immune responses. Cell Death Differ 27:1451-1454. https://doi.org/10.1038/ s41418-020-0530-3

2. Sharquie IK et al (2020) Electron J Gen Med 17(6):em229. https://doi.org/10. 29333/ejgm/7892

3. Zheng YQ, Naguib YW, Dong Y, Shi YC, Bou S, Cui Z (2015) Applications of bacillus Calmette-Guerin and recombinant bacillus Calmette-Guerin in vaccine development and tumor immunotherapy. Exp Rev Vac 14(9):1255-1275

4. World Health Organization (WHO) 2020. https://www.who.int/dg/speeches/ detail/who-director-general-s-opening-remarks-at-themedia- briefing-oncovid-19\%2D\%2D-4-may-2020. Accessed 4 May 2020

5. Fine PE (1995). Variation in protection by BCG: implications of and for heterologous immunity. Lancet. 346(8986):1339-1345. https://doi.org/10. 1016/s0140-6736(95)92348-9 PMID:7475776

6. Moorlag SJCFM, Arts RJW, van Crevel R, Netea MG (2019). Nonspecific effects of BCG vaccine on viral infections. Clinical microbiology and infection. 25(12):1473-1478. https://doi.org/10.1016/j.cmi.2019.04.020 PMID: 31055165 
7. Gursel M, Gursel I (2020). Is global BCG vaccination coverage relevant to the progression of SARS-CoV-2 pandemic? [Published online ahead of print, 2020 Apr 6]. Med Hypotheses. 109707. https://doi.org/10.1016/j.mehy.2020 109707

8. WHO-UNICEF estimates of BCG coverage, last update 15 July 2019. https:// apps.who.int/immunization_monitoring/globalsummary/timeseries/ tswucoveragebcg.html.

9. Hegarty PK, Sfakianos JP, Giannarini G, DiNardo AR, Kamat AM (2020) COVID-19 and bacillus Calmette-Guérin: what is the link? Eur Urol Oncol 3: 259

10. Abundance Foundation (2020). Crucial research testing efficacy against COVID-19 of most widely used vaccine in the world| Abundance Foundation [Internet]. Available at: https://www.abundance.org/crucialresearch-assessingefficacy-in-preventing-covid-19-of-widely-used-vaccinefortuberculosis-called-bcg/

11. Moorlag SJCFM, Arts RJW, van Crevel R, Netea MG (2019) Non-specific effects of BCG vaccine on viral infections. Clin Microbiol Infect 25(12):1473-1478

12. Sala G, and Miyakawa T. 2020. "Association of BCG vaccination policy with prevalence and mortality of COVID-19." Preprint.

13. Li Y, Zhao S, Zhuang Z, Cao P, Yang L, He D. (2020). The correlation between BCG immunization coverage and the severity of COVID-19. Available at SSRN 3568954

14. Shet, A, Ray D, Malavige N, Santosham M, and Bar-Zeev N. (2020), "Differential COVID-19-attributable mortality and BCG vaccine use in countries." medRxiv, 2020.04.01.20049478.

15. Aaron M, Reandelar JM, Fasciglione K, Roumenova V, Li Y, Otazu GH (2020). "Correlation between universal BCG vaccination policy and reduced morbidity and mortality for COVID-19: an epidemiological study." Preprint.

16. Dayal D (2020). We urgently need guidelines for managing COVID-19 in children with comorbidities. Acta Paediatr. https://doi.org/10.1111/apa.15304.

17. Fukui M, Kawaguchi K and Matsuura H, Does TB vaccination reduce COVID-19 infection? No evidence from a regression discontinuity analysis (April 9, 2020). Available at SSRN: https://ssrn.com/abstract=3572090 or https://doi.org/10. 2139/ssrn.3572090

18. Hamiel U, Kozer E, Youngster I. 2020. SARS-CoV-2 rates in BCG-vaccinated and unvaccinated young adults. JAMA. Published online May 13, 2020 https://doi.org/10.1001/jama.2020.8189

\section{Publisher's Note}

Springer Nature remains neutral with regard to jurisdictional claims in published maps and institutional affiliations.

\section{Submit your manuscript to a SpringerOpen ${ }^{\circ}$ journal and benefit from:}

- Convenient online submission

- Rigorous peer review

- Open access: articles freely available online

- High visibility within the field

- Retaining the copyright to your article

Submit your next manuscript at $\boldsymbol{\nabla}$ springeropen.com 